\title{
A Sociotechnical Approach to Analyse Pharmaceutical Policy And Services In Primary Health Care
}

\author{
Noemia Liege Maria Cunha Bernardo \\ Universidade do Vale do Itajai \\ Luciano Soares \\ Universidade Federal de Santa Catarina \\ Silvana Nair Leite ( $\nabla$ silvana.nair@hotmail.com) \\ Universidade do Estado de Santa Catarina https://orcid.org/0000-0002-5258-9684
}

\section{Research article}

Keywords: Pharmaceutical Services, Sociotechnical Analyses, Primary Health Care, Pharmaceutical Policy, Pharmaceutical System

Posted Date: June 11th, 2020

DOI: https://doi.org/10.21203/rs.3.rs-32157/v1

License: () (i) This work is licensed under a Creative Commons Attribution 4.0 International License. Read Full License 


\section{Abstract}

Background: Access to medicines and its rational use are persistent global concerns. It have a major impact on the quality and sustainability of the health system and on the health outcomes. In Brazil, access to medicines is a legal right and municipal government have the duty to ensure access and the best use of medicines in primary health care public facilities, stablishing the local Pharmaceutical Policy and Services (PPS) system. This article presents and analyses an innovative experience of diagnosis of municipal PPS as a sociotechnical system, aiming to prepare the interventions in the system.

Methods:We adopted a multi-methods approach and various data sources were used. Sociotechnical theory was the framework of the methodology of evaluation and design of systems, analysing the Components of External System (health system, stakeholders, financing) and Components of the Internal System (Goals, Management, Workforce, Infrastructure, Processes, Technology and Culture).

Results:The component "aim" was identified as the central element of the system. The other system components interrelate with its scope. Medicines availability was a key part of the PPS architecture. Lack of central coordination, pharmaceutical services without central management and a fragmented organization prevented an integrated internal planning, and with other sectors. The stakeholders and documents referred only technical elements of the system: infrastructure, technical process and technology. The social components of workforce and culture were not mentioned in the Municipal Health Plan. People are essential socio-technical elements, as well the components affecting them, but they are not privileged in the system. The organizational culture established was the culture of isolation: "each one does his own".

Conclusions:The municipal PPS emphasized medicines and technical components and had limited scope as a public policy. It had constrained the characteristics of a complex and open system. Stakeholders understood PPS as a set of technical processes, without planning or integration. PPS has had a great development in Brazil in the last twenty years. A new level of development to ensure the populations right to access of treatment requires a turning point of strategy to understand municipal PPS as a sociotechnical system.

\section{Background}

Access to medicines and its rational use are persistent global concerns. These issues have a major impact on the quality of the health system and, consequently, on the health outcomes [1]. The expansion of access to medicines was listed as one of the 10 biggest problems that demand attention from Work Health Organization [2]. A systematic review of rational use of medicines showed the inappropriate use of pharmaceutical products remains a public health problem [3]. It included 900 studies from 104 countries. Ensuring access to medicines and their proper use is a mission that requires coordinated action. It cannot be based on either market decisions or collective common sense.

In Brazil, access is a mission defined as a public policy [4]. The National Pharmaceutical Policy defines services and responsibilities at all levels of governance of the Unified Health System (SUS) to guarantee access to medicines and pharmaceutical services. With the decentralization of the health system, municipalities assumed a "series of responsibilities that demand the mobilization of knowledge and technical, managerial, and political skills relative to pharmaceutical policy and services" [5]. These new responsibilities, especially from the beginning of the 2000s, demanded theoretical-methodological definitions and operational services in the health departments that were well described by Marin et al. (2003) and disseminated as the "pharmaceutical policy and services cycle".

This "cycle" defines an interconnected set of processes, involving selection, programming, acquisition, storage, distribution, and use of medicines. That framework was crucial for establishing the importance and technical-scientific characteristics of a new field of public health in Brazil. In almost two decades, the role of pharmaceutical professionals and technical management in the access to and rationality in the use of medicines has been established [6]. The high level of access to medicines for chronic diseases in primary healthcare (PHC) achieved a prevalence of $94.3 \%$ in Brazil between 2013 and 2014 [7].

However, some important weaknesses can be identified in the prevailing theoretical framework used in recent studies on the organization of the pharmaceutical policy and services (PPS) system in primary health care (PHC). Particularly, research reports highlight the lack of integration of policies and practices for the organization of pharmaceutical services with a comprehensive approach to the health-disease process [8, 9, 10, 11].

Beyond the unequal access to medicines, gaps in technical issues for the institutionalization of PPS in PHC were also uncovered, such as low availability of PPS manager jobs; few pharmacy and therapeutics committees and few lists of essential medicines; poor structuring of pharmaceutical services; low availability of computerized systems; poor logistics, management, and pharmaceutical care in health facilities; limited integration between pharmacists and the health team; limited intersectoral governance; low participation of PPS managers in social control councils [10, 12, 13, 14].

This scenario outlines the premise that the complexity involved in PPS demands its understanding as a complex system, whose operation is a better explainable phenomenon from an interconnected multidimensional perspective. With this in mind, this article presents and analyses an in-service experience of the diagnosis of a municipal PPS as a sociotechnical system. The theory of sociotechnical systems is a contemporary way to provide support for various aspects of technical and human activities in organizational development. It consists of interdependent subsystems, organized as an open system that interacts with the external environment and with its own internal environment [15]. First characterized organizations as sociotechnical systems made up of two subsystems, the technical and the social, which work together to accomplish the organization's task or mission [16].

In the experience analysed in this study, the sociotechnical theory was the framework of the methodology of evaluation and design of systems, from the classic studies by Trist (1981) and by several authors who have been developing the theory application in different sectors. In health systems, this theory has been applied to evaluate strategies for incorporating technological innovations [17, 18, 19, 20], and also in pharmaceutical services [20, 21]. However, this is the first approach of the theory of sociotechnical systems to characterize and analyse the PPS of a municipality in Brazil, aiming to prepare the interventions in the system. 


\section{Methods}

The present study was performed during the situational diagnosis of PPS, which was part of implementing the pharmaceutical field in an interprofessional collaboration residency course in PHC for04 municipalities in the state of Santa Catarina/Brazil. Its reports an in-service experience with the development of a socio-technical assessment designed to promote the reorientation of PPS in PHC at the municipal level. The results of the diagnostic are presented about one of the municipalities participating in the project, where the study was conducted in partnership with the Municipal Health Secretariat (MHS).

\section{The place of study}

The municipality studied located in the European Valley, in Santa Catarina, has an estimated population is 135 thousand inhabitants, the Human Development Index (HDI) is approximately 0.8 and the predominant economic activities are industry, agriculture and services [22].

\section{Data collection}

Various data sources were used to cover the scope of the interpretation in a sociotechnical analysis. The collection was related to data from the municipal PPS until June 2017

a)Sources, search strategies and description of the collected data

The search in the Municipal Transparency Portal, Municipal laws, IBGE (Brazilian Institute of Geography and Statistics) and SIDEMS (System of Sustainable Municipal Development Indicators) resulted in the extraction of the data categories described in Table 1.

Table 1

Data extracted from consulted databases

\begin{tabular}{|c|c|c|}
\hline Database & Link & Description of the data \\
\hline $\mathrm{IBGE}^{1}$ & https://cidades.ibge.gov.br/ & $\begin{array}{l}\text { Year of Installation, territorial area, distance from the capital, estimated } \\
\text { population, human development index, predominant economic activity, GDP } \\
\text { per capita, percentage of urban households [22]. }\end{array}$ \\
\hline SIDEMS $^{2}$ & https://indicadores.fecam.org.br/index/index/ano/2020 & $\begin{array}{l}\text { Municipal sustainable development index (IDMS), health situation analysis } \\
\text { [23]. }\end{array}$ \\
\hline $\begin{array}{l}\text { Municipal } \\
\text { Transparency } \\
\text { Portal }\end{array}$ & https://brusque.atende.net/?pg=transparencia\#!/ & Expenses with pharmaceutical policy and services [24]. \\
\hline
\end{tabular}

In the analyses of documents, the sources were the chapters "Structure of the health care network" and "Pharmaceutical Policy and Services" of the Municipal Health Plans of 2010 and 2014, Guidelines for PPS and of the evaluation report of the municipal controllership. Data were also collected from the Government Plan presented at the 2016 Municipal Elections to the municipality and the PPS regulations published until 2017.

The collected data were related to:

- Municipal health system: infrastructure, organizational structure, Family Health Strategy coverage, workforce description of the Family Health Support Center, health funding and financial circumstances;

- PPS: goals, organizational structure, available workforce and infrastructure, processes and organizational culture.

An institutional documentary published on the proposal for reorienting PPS in the municipality provided testimonies from managers, pharmacists, coordinators of health units, doctors and patients of municipal health services (available at https://www.youtube. com / watch? v = MqtG8ml8Srw).Another data were collected from articles on issues related to the PPS in newspapers published in the city between January 2016 and February 2017 , radio stations and blogs that carry news about the municipality. Search strategy combined the terms "medicine" and "pharmaceutical policy and services".

b) Assessment Matrix of the Management Capacity of municipal PPS

We collected the data with the instruments from Assessment Matrix of the Management Capacity (AMMC) of the municipal PPS. Manzini and Mendes [9] developed and first used AMM Cof the PPS in Santa Catarina municipalitiesvalidated the instruments. The matrix framework uses Carlos Matus' management assumptions, first adopted by Barreto and Guimarães [25].

The collection was performed at the pharmacies located on municipal health department. One pharmacy dispenses PHC medicines, another provides specialized or under judicial medicines. Other places included: 23 pharmacies located in the PHC centers and the pharmaceutical center for distribution and supply, and the Health Municipal Secretariat. Participants of this phase were: 01 health secretary, 01 PHC Coordinator, 01 pharmacist, 17 nurses / coordinators of the PHC Centers, 18 doctors, 18 pharmacy assistants and 86 patients.

\section{Data analysis}

The documentsevaluation was performed by content analysis. The financial and rates data were used as original data. The social and technical components of the municipal PPS system were typified according to the socio-technical structure described in Fig. 1. 
Insert Fig. 1

These components were chosen after researching the literature on the analysis of socio-technical systems in the health field [17, 19, 20, 21, 26, 27, 28] and in other sectors [16, 29, 30, 31, 32, 33, 34]. PPS organization in Brazil was another topic sought[9, 10, 25, 35, 36].

The results were analyzed based on the sociotechnical dimensions, on the researchers' experiences and were typified according to the components described in Table 2.

Table 2

Environmental(Scenario) and the internal systems components of the Sociotechnical System of PPS in PHC.

\begin{tabular}{|c|c|c|}
\hline Components & Literature description & Adaptation to the study \\
\hline \multicolumn{3}{|c|}{ Components of External System: Municipal Management System; Municipal Health System } \\
\hline Environment & $\begin{array}{l}\text { Context where the study's focus system is } \\
\text { inserted. }\end{array}$ & $\begin{array}{l}\text { Characterization of the environment where PPS is inserted according to: objective, } \\
\text { guidelines and society's goals for PPS. }\end{array}$ \\
\hline $\begin{array}{l}\text { Interested } \\
\text { parts }\end{array}$ & $\begin{array}{l}\text { Objective of the system for patients, } \\
\text { management, suppliers and representatives of } \\
\text { civil society }\end{array}$ & $\begin{array}{l}\text { PPS expected outcomes from the perspective of municipal management, the health } \\
\text { department and patients. }\end{array}$ \\
\hline Financing & $\begin{array}{l}\text { Economic situation under which the system is } \\
\text { developed and what financial resource the } \\
\text { system should operate. }\end{array}$ & Annual financing of PPS. Budgeted amount and amount paid. \\
\hline Regulations & Rules and laws that regulate the organization & Rules and municipal laws that regulate the organization and activities of PPS. \\
\hline \multicolumn{3}{|c|}{ Components of the Internal System } \\
\hline Goals & $\begin{array}{l}\text { Targets of the system, its operation or that } \\
\text { generated the demand for its construction. }\end{array}$ & Objective of municipal PPS for the different healthcare actors. \\
\hline Management & $\begin{array}{l}\text { Organizational structure and its technical } \\
\text { operations. }\end{array}$ & $\begin{array}{l}\text { Organizational structure of municipal PPS and its management capacity in PHC. } \\
\text { Dimensions: organizational, operational and sustainability. }\end{array}$ \\
\hline Workforce & $\begin{array}{l}\text { Number of people able to participate in the } \\
\text { social division of labour process. }\end{array}$ & $\begin{array}{l}\text { Group of people with the capacity and ability to carry out PPS activities. Workgroups } \\
\text { where tasks are performed. }\end{array}$ \\
\hline Structure & $\begin{array}{l}\text { Equipment or the physical structure required for } \\
\text { the performance of system activities. }\end{array}$ & Structures and infrastructure by workgroup of the PPS system. \\
\hline Processes & $\begin{array}{l}\text { Main activities that are part of the system, } \\
\text { including the main and routine activities }\end{array}$ & $\begin{array}{l}\text { Main activities by PPS workgroup in PHC. Why does the unit of work exist? How does } \\
\text { it communicate with the system and the environment in its technical and relational } \\
\text { aspects? }\end{array}$ \\
\hline Technology & $\begin{array}{l}\text { Equipment and methods used to produce } \\
\text { products or services. A health technology can } \\
\text { be defined as a way, knowledge and the } \\
\text { instruments used to produce health actions. }\end{array}$ & $\begin{array}{l}\text { Description of drug treatments and instruments used for their access, use and } \\
\text { monitoring. Drug treatment: Criteria and places for selection, access and monitoring } \\
\text { of outcomes. Instruments: Municipal List of Medicines, Electronic Health Record, } \\
\text { protocol, computerized system. }\end{array}$ \\
\hline Culture & $\begin{array}{l}\text { Organizational culture of the system, the way it } \\
\text { thinks and acts, the beliefs and values held in } \\
\text { organization and society. }\end{array}$ & $\begin{array}{l}\text { Organizational culture of PPS on three aspects. Symbols: names, logos and physical } \\
\text { characteristics used to convey the organization's image. Rituals: usual and repeated } \\
\text { actions within an organization. Ideology. beliefs, moral principles and values provide } \\
\text { the basis for organizational decision making. }\end{array}$ \\
\hline
\end{tabular}

\section{Ethical Aspects}

This study is part of a project called "Application of Sociotechnical Theory in the Reorientation of Pharmaceutical Care in Primary Health Care". It was approved by the Univali Research Ethics Committee (CAAE: 28471320.2.0000.0120).All participants signed a written form of consent after having received information about the study. The analysis was based on an existing database and information on the process of reorienting PPS in PHC in four municipalities in Santa Catarina.We do not identify the municipality by name to prevent identifying individual participants. Individual participants indicated by professional title and job position.

\section{Results}

The results of the socio-technical evaluation of PPS in PHC will be presented below in two sections: 1 - organization of the environment in terms of stakeholders, objective; financial circumstances and health funding, the general regulations and those related to PPS system performance; and 2 - description of the of socio-technical elements of PPS in PHC.

\section{Organization of environment}

In 2016, the sustainable municipal development index (IDMS) was 0.726 (scale from 0.00 to 1.00), a medium high level. In the economic and social participation dimensions, the levels were low (0.630) and medium low (0.524), respectively. The analysis of the health situation falls within a medium high level, with index of 0.798.In 2017, the municipality experienced weaknesses in the economic and political contexts, attributed to the impeachment of the mayor and the vice-mayor in 2015. This scenario was accompanied by a strict control process, especially in the acquisition of products, and in the hiring of services and staffing by public management, with a financial surplus at the end of 2016 [24]. 
The main stakeholders identified in the municipality's PPS were the social control council, municipal health department and the press. The Municipal Health Plan (2014-2017) embraces the guarantee of the dispensation of medicines from Municipal List of Medicines (called REMUME) and, secondarily, building a laboratory to produce herbal medicines. The Table 3 illustrates expectations and demands about PPS based on the summary of reports published in local media outlets. The demands regarding the results to be produced by PPS focus on the availability of medicines, given the understanding that the system failed to meet this expectation.

Table 3

Narrative from articles published in the municipal media about access to medicines in the Municipal Health Network

\begin{tabular}{|c|c|c|c|}
\hline Date & Headline & Narrative & Source \\
\hline $1 / 26 / 16$ & $\begin{array}{l}\text { Lack of } \\
\text { medication }\end{array}$ & $\begin{array}{l}\text { "The article on the cover of the newspaper Municipio Dia a Dia, } \\
\text { last Thursday (21), speaks of the lack of medicines in public } \\
\text { pharmacies. According to the report, there are } 53 \text { drugs missing } \\
\text { from the downtown basic pharmacy, and the list contains drugs } \\
\text { prescribed very frequently, as is the case of the omeprazol, } \\
\text { amoxicillin and buscopan". }\end{array}$ & $\begin{array}{l}\text { http://araguaiabrusque.com.br/noticia/geral/falta-de- } \\
\text { medicamentos-29926 }\end{array}$ \\
\hline $5 / 27 / 16$ & $\begin{array}{l}\text { City Hall } \\
\text { clarifies } \\
\text { about lack } \\
\text { of } \\
\text { medicines } \\
\text { in the } \\
\text { Municipal } \\
\text { Health } \\
\text { Network }\end{array}$ & $\begin{array}{l}\text { "The Health Secretariat informs that some medications are } \\
\text { missing in the PrimaryHealthCenters and in the Basic } \\
\text { Pharmacy, located in the Center. The items have already been } \\
\text { requested and the situation can be regularized at any time. } \\
\text { According to the folder, the situation occurs due to several } \\
\text { situations, such as lack of raw material for production, } \\
\text { discontinuation of imports and lack of supplier. However, some } \\
\text { of the remedies await only the supply of the bidding company". }\end{array}$ & $\begin{array}{l}\text { https://brusque.portaldácia.com/noticias/saude/prefeitura- } \\
\text { de-brusque-esclarece-sobre-falta-de-medicamentos-na-rede- } \\
\text { municipal-de-saude }\end{array}$ \\
\hline 9/19/17 & $\begin{array}{l}\text { Patients } \\
\text { suffer from } \\
\text { lack of } \\
\text { medication } \\
\text { to relieve } \\
\text { back pain }\end{array}$ & $\begin{array}{l}\text { "Patients who have a back problem, suffer from severe pain and } \\
\text { need Tramadol to relieve symptoms since the last week, face } \\
\text { the shortage of medication. }\end{array}$ & $\begin{array}{l}\text { https://omunicipio.com.br/pacientes-sofrem-com-falta-de- } \\
\text { medicamentos-para-aliviar-dores-nas-costas/ }\end{array}$ \\
\hline
\end{tabular}

Regarding the financing of PPS in 2017, the budget was R\$ 5,245,270.18.Data from the municipality's transparency portal show that between 2014 and 2017 , actual expenses with PPS represented, respectively, 4.5\%, 3.8\%, 4.3\% and 4.7\% of the expenses incurred by the municipal health system, which grew at a constant rate in the period. PPS payments increased from R\$ 3,110,001.97 in 2014 to $R \$ 4,040,022.63$ in 2017, varying from R\$ 25.98 to $R \$ 31.36$ per capita. The 2016 management report points out that "considering the high consumption of medicines by patients, this policy [PPS] was insufficient to reach its totality in the face of a lack of resources". The 2017 report described a balance of R\$ 366,312.02 not spent on PPS. The program and action expenses section of the municipality's transparency portal shows that in the action "Family Health Strategy and Pharmaceutical Assistance", the percentage of the executed budget was $99.68 \%$ in $2014,96.70 \%$ in $2015,93.88 \%$ in 2016 and $84.16 \%$ in 2017.

The municipality's 2015 Annual Health Program (AHP) defined the "Guarantee of pharmaceutical assistance within the scope of SUS" in its Guideline H translated into objective $\mathrm{H} 1$ of "Ensuring the availability of medicines to the population" with the following planning:

Table 4

PPS goals, indicators, actions and budget in the 2015 AHP in the municipality.

\begin{tabular}{|c|c|c|c|c|}
\hline Goal & Indicator & Action & Budget (R\$) & $\begin{array}{l}\text { Budget } \\
\text { origin }\end{array}$ \\
\hline \multirow[t]{3}{*}{$\begin{array}{l}\text { Implement actions to dispense medication and } \\
\text { inventory maintenance regularly }\end{array}$} & \multirow[t]{3}{*}{$\begin{array}{l}\text { number of actions } \\
\text { implemented }\end{array}$} & $\begin{array}{l}\text {-Take actions to ensure adequate } \\
\text { dispensing of medication; }\end{array}$ & \multirow[t]{3}{*}{$5,000.00$} & \multirow[t]{3}{*}{$\begin{array}{l}\text { Municipal } \\
\text { resource. }\end{array}$} \\
\hline & & -Promote regular stock maintenance; & & \\
\hline & & $\begin{array}{l}\text {-Ensure adequate distribution in the } \\
\text { municipal health network. }\end{array}$ & & \\
\hline \multirow[t]{3}{*}{ Maintain the supply of medicines regularly. } & \multirow[t]{3}{*}{$\begin{array}{l}\text { number of pharmacies } \\
\text { in operation }\end{array}$} & $\begin{array}{l}\text {-Ensure the distribution of selected drugs } \\
\text { on a regular basis; }\end{array}$ & \multirow[t]{3}{*}{$2,034,534.40$} & $\begin{array}{l}\text { Federal } \\
\text { resource. }\end{array}$ \\
\hline & & -Regular stock maintenance; & & \multirow{2}{*}{$\begin{array}{l}\text { Municipal } \\
\text { resource. }\end{array}$} \\
\hline & & $\begin{array}{l}\text {-Adequate distribution in the municipal } \\
\text { health network }\end{array}$ & & \\
\hline
\end{tabular}

Municipal PPS regulations, published until 2017, were related to:

1. a) Complementary Law No. 224/2014: institutes the Municipal Health Code, which defines pharmacy as a health service and medicines as products subject to sanitary control [38].

2. b) Normative No. 005/2015: It was defining the organization and assignments of the tasks, the prescription, dispensing and supply of medicines and the parameters for the functioning and structure of the services [39].

3. c) Decree No. 7826, July 8, 2016: Disciplines procedures to be adopted by doctors and dentists, municipal civil servants and service providers for the Unified Health System at the municipal level in the prescription of medications [40]. 


\section{Sociotechnical characterization of the municipal PPS}

\subsection{Goal of the Sociotechnical System of PPS in PHC}

The data collected were described and referred by several stakeholders that affected the social and technical factors of PPS, as shown by the evidence below.

One promise of the mayor-elect campaign (2017-2020) was to increase the accessibility of medicines in health facilities. The government plan carried the slogan "Medicines basic and of chronic use to the entire needy community". In the municipal health plans (MHP) for the periods 2010-2013 and 2014-2017, the objectives focused on the accessibility of medicines, as described in Table 5.

Table 5

Description of the purpose and goal for PPS in the MHP 2010-2013 and 2014-2017

\begin{tabular}{|c|c|c|}
\hline Period & Purpose & Goal \\
\hline \multirow{3}{*}{$\begin{array}{l}2010 \\
\text { to } \\
2013\end{array}$} & \multirow{3}{*}{$\begin{array}{l}\text { "The municipal PPS's main purpose is to provide regular and free supply of } \\
\text { selected drugs, in order to contemplate the outpatient drug treatment of the } \\
\text { different pathologies that affect the population". }\end{array}$} & $\begin{array}{l}\text { - Ensure the supply of medicines to all SUS patients in } \\
\text { accordance with the list of selected medicines. }\end{array}$ \\
\hline & & - Constantly review the list of selected medicines. \\
\hline & & - DeployPhytotherapic Handling Pharmacy. \\
\hline \multirow[t]{2}{*}{$\begin{array}{l}2014 \\
\text { to2017 }\end{array}$} & \multirow[t]{2}{*}{$\begin{array}{l}\text { "Guarantee the dispensation medicinesof municipal list to the population". } \\
\text { Implement the herbal medicine production laboratory. }\end{array}$} & $\begin{array}{l}\text {-Consolidate drug purchase, dispensing and inventory control } \\
\text { routines, and the use of the G-MUS management system to } \\
\text { improve purchase and dispensing monitoring. }\end{array}$ \\
\hline & & $\begin{array}{l}\text {-Forward a fundraising project at the Ministry of Health to } \\
\text { implement the herbal medicine laboratory. }\end{array}$ \\
\hline
\end{tabular}

\subsection{PPS Management in PHC}

In 2017, the municipal PPS did not have a formalized organizational structure, there was no coordination of the system, nor the formation of a PPS team. Six pharmacists work in services and with tasks considered independent. A representation of this organizational structure is shown in Fig. 2 to illustrate the nature of administrative relationships.

\section{Insert Fig. 2}

Table 6 describes managerial and sociotechnical dimensions of the Management Capacity Assessment of municipal PPS in 2017. 
Management component

Organizational

Operational

Sustainability

Total

Workforce component

Condition of existence of the PPS Coordination in the Municipal Health Department (MHD).

Degree of decision-making autonomy of the PPS Coordination.

Profession of the PPS coordinator.

Participation of pharmacists in the preparation of the Municipal Health Plan.

Participation of PPS coordination in health programs or activities in the municipality (in other MHDsectors).

Responsibility for defining the programming parameters for distributing medicines to health units.

Health units with pharmacists working in the team.

Pharmacists trained in PA, management, public health or related fields in the past 2 years.

Type of employment contract of the PPS coordinator.

Pharmacist position in the list of municipal public service positions.

Total

Infrastructure component

Integration of the PA information system with that used in the health care network.

Instruments to assess physical and environmental conditions to store medicines (external and internal conditions, lighting, refrigeration, security).

Investments in infrastructure in the last 4 years in PPS services.

Total

63

$7 \quad 7$

Processes component

Pharmacists and health unit coordinators recognize the existence of PPS coordination.

Regular functioning of the Pharmacy and Therapeutics Committee in the last year.

Pharmacists know the Municipal Health Plan.

PHC drugs purchased based on the schedule.

Prescribed medicines based on lists of medicines adopted by the municipality.

Medicines out of date available for dispensing.

Health services have a waste management plan.

The pharmacist's productivity record has a defined procedure.

Spending on medicines to meet legal demands in relation to the budget to buy medicines, in the last year.

Schedule for regular distribution of medicines to health units: monthly, biweekly or weekly.

Prescribers receive information about the availability of medicines in pharmacies at health facilities.

Prescribers know how to find updates to the municipal list of medicines.

Amount of medications available in health facilities suitable to meet patients' demands (perceptions of health secretary, PA coordinator, pharmacists and prescribers). Diversity of medications available in health facilities suitable to meet patients' demands (perceptions of health secretary, PA coordinator,
pharmacists and prescribers).

Procedures for monitoring the PPS and using data to plan actions.

Resources diversity introduced in the municipal PPS in partnership with the State PPS.

\begin{tabular}{lll}
8 & 0 \\
\hline 6 & 0 \\
\hline 8 & 8 \\
\hline 6 & 0 \\
6 & 6 \\
\hline 6 & 6 \\
\hline 5 & 0 \\
\hline 7 & 0 \\
\hline 6 & 6 \\
\hline 6 & 6 \\
\hline 7 & 7 \\
\hline 8 & 8 \\
\hline 4 & 1 \\
\hline 4 & 2 \\
\hline 6 & 0 \\
\hline 7 & 0 \\
\hline
\end{tabular}

Source: the authors. Legend: MS: maximum score; SO: score obtained. 


\begin{tabular}{|c|c|c|}
\hline Description & MS & so \\
\hline Shared definitions about goals, guidelines and targets PPS in the Municipal Health Plan. & 10 & 0 \\
\hline Official means to receive criticisms and suggestions about medicines from patients (referred by the health unit coordinator). & 7 & 7 \\
\hline Official means to receive criticisms and suggestions about medicines from patients (referred by patients). & 8 & 3 \\
\hline Total & 125 & 70 \\
\hline \multicolumn{3}{|l|}{ Technology component } \\
\hline Pharmacy and Therapeutics Committee has formal institution at the MHD. & 5 & 0 \\
\hline Technical criteria used to prepare the medication schedule. & 6 & 0 \\
\hline Municipal Medicines List Availability. & 6 & 5 \\
\hline Municipal List of Medicines includes drugs are outside National List of Essential Medicines or lists agreed in SUS. & 5 & 5 \\
\hline Instruments to standardize medication dispensing (SOP, manuals). & 6 & 0 \\
\hline Total & 28 & 10 \\
\hline \multicolumn{3}{|l|}{ Organizational culture component } \\
\hline $\begin{array}{l}\text { Communication strategies between health units and PPS coordination to resolve medications issues (referred by health unit coordinators } \\
\text { and pharmacists). }\end{array}$ & 7 & 7 \\
\hline Articulation between PPS coordination, the Family Health Strategy coordination and Community Agents Team & 7 & 0 \\
\hline Partnership between the municipality's PPS Coordination and the State PPS Coordination. & 7 & 0 \\
\hline PPS agenda at the meetings of the Municipal Health Council in the last 4 years. & 10 & 3 \\
\hline Total & 31 & 10 \\
\hline
\end{tabular}

\section{INSERT Table 6}

\subsection{Workforce of municipal PPS in PHC}

Ten indicators of Assessment Matrix of the Management Capacity of municipal PPS correspond to sociotechnical dimension 'workforce', according Table 6. Coordination was the responsibility of two nurses and an administrative assistant. Six pharmacists were active staff of the PPS, two with a fixed-term employment contract and four civil servants. The experience of pharmacists in the municipal health service ranged from 01 to 05 years.

Nursing technicians and assistants were the major workforce to dispense medicines in health facilities. There was no predefined scale to work and the premise was "whoever is out of activity stays at the pharmacy". The health services coordination (usually a nurse) asked for medicines from the warehouse. In the Central Pharmacy Dispensing Unit (UD1), there were two pharmacists and six assistants (a nurse and five administrative staff). These pharmacists planned PPS services in an independent way.

We found a pharmacist in the dispensing services in specialized care service center (UDI2). Two pharmacists and three assistants in specialized and judicial dispensing centers (UD2). And one pharmacist worked at the Pharmaceutical Distribution and Supply Center. In all these services, pharmacists planned PPS activities thenselves. None of the pharmacist had previous training to work in the public service or in PPS, nor have they received training in the area in the past two years. The quotes below show PHC professionals opinions about the pharmacists qualifying the healthcare processes:

PHC manager: "When I was at the PHC, we didn't have this process in place yet, I can't say it was a mess because it was part of the process, but we have two or three technicians in each health center and each one who had a little time at the pharmacy and dispensing medication, with that we had a lot of puncture in the stock, there were several complications".

Family Health Strategy Doctor: "I believe that a pharmacist fixed in the PHC center would help us a lot, due to the knowledge, you know, for being a qualified professional for that. Although we have a technician in a finished shift, but we do not have the technical knowledge of that job, which has to be performed".

\subsection{PPS Infrastructure and Processes in PHC}

Infrastructure component has 03 indicators described in Table 6. We analysed 22 UDI in PHC, UD1 (PHC medicines) and the Pharmaceutical Distribution and Supply Center. All facilities had internal and external areas in good conditions, allowing hygiene. The structure offered no risk to patients and employees, meeting the recommended standards. We found computers and internet access in all units. Fifteen percent of facilities had insufficient number of computers. These equipments had no technical maintenance for two years.An information system manages the stock of medicines in PHC. A third party company provides the system.

The processes component include 23 indicators. It was detailed in Table 6. In 2017, PPS services performed 20,406 attendance, as shown in Table 7. 
Table 7

Number of attendance in dispensing services, items dispensed and its price in 2017

\begin{tabular}{|llllll|}
\hline Description & Patients & Numberofvisits & Number of items & Quantity of dispensed items & Values of total dispensed items (R\$) \\
\hline Daily average $^{1}$ & 928 & 971 & 145 & 71,043 & $8,375.00$ \\
\hline Monthly Average $^{2}$ & 20,406 & 21,355 & 3,193 & $1,562,936$ & $184,254.00$ \\
\hline
\end{tabular}

Source: the authors. 1- daily average calculated based on the data of dispensation of July 1st days to December 31st of 2017; 2- monthly average calculated based on six month dispensation data.

In 2017, PPS services included scheduling, ordering purchases, storing and dispensing medications. The procurement department of the city hall held bids to buy medicines with no pharmacist participation. We observed no services related to: 1 ) discard health care waste (there is no Health Services Waste

Management Plan); 2) review patients' pharmacotherapy or perform pharmacotherapeutic follow-up; 3) provide technical support for the health team or health education for patients and the community. There were no standard technical criteria for programming, purchasing, distributing and dispensing drugs. Only in Central Pharmacy Dispensing Unit (UD1) we found defined routines and procedures. There was no procedures related to pharmaceutical care and matrix support for healthcare teams.

Pharmacists inferred the lack of standardized technical parameters can compromise availability of medicines. The availability of drugs was only $60 \%$ and there was a large amount of drugs out of date.Several actors point to other deficits in PPS services. They attribute to this, problems in the work process, waste of products, lack of access and treatments with inferior quality. The quotes below illustrate the statements.

Secretary of Health: "... the current management found primary healthcare with 'unstructured teams by the lack of professionals', lack of medicines - 60\% of the items listed in the Municipal List of Medicines, 500 kilos of expired medicines and an empty warehouse.

Pharmacists from Pharmaceutical Distribution and Supply Center:

"When I started at the warehouse, our purchases were based on the transfers that we made to the health units and then these values, these amounts that we had, they were not very reliable, because they were not based on the real demand that we had in the units at that time".

"I worked in the health store, in the medication sector and in the period 2014-2016, we did not have stock control, we did not have the management of stock control in health units, nor which distributions in the stockroom. The distribution was made to health units once a month and that was the supply that the units have".

Family Health Strategy doctor: "We had a very serious problem, in terms of user access, the medications in the unit, a difficulty due to the lack of professionals to take care of the medication release and this influenced the entire work process of other professionals".

PHC center Coordinator: "So three years ago when I started in the municipality, at the health unit, PPS was very deficient in many ways, in the sense of stock control, waste, user guidance, professional guidance, that we didn't have a lot of accessibility to some information and guidance regarding the delivery of the medication and PPS.

PHC Manager: "When I was at the unit, we didn't have this process in place yet, I can't say it was a mess because it was part of the process, but we have two or three technicians in each health unit and each one who had a little time went into the pharmacy and dispensed medication. With that, we had a lot of puncture in the stock, and there were several complications like that. Even for the nurse, it was difficult to charge someone who was a continuous process and walked smoothly".

\subsection{Technology in PHC}

The technology component consists of 05 indicators, detailed in Table 6 . It includes drug treatment and the instruments for its access and monitoring. The municipality regulates the prescription and dispensing of medicines. It defines facilities to provide pharmaceutical services, as indicated in Fig. 2 . The municipality's PHC Medicines List had the National Essential Medicines List as reference. In 2017, 202 drugs were available. About 16\% (32) did not appear in 2017 edition of the National Essential Medicines List. Some of these items had no prescription for over a year.

There was a municipal program for access to medicines not selected by PPS. Patient should submit a medical request based on scientific evidence to have access. This program allowed access to 148 medicines. Most of them outside the National List of Essential Medicines. But, such products had therapeutic equivalents on the municipality's Medicines List. The program cost was R 540 thousand a year. The municipality's attorney general analized medicines lawsuits, without PPS or the Health Department support. There was no record of expenses with access through this route. We observed some constraints on the instruments used in the municipality's PPS:

a) Municipality's Medicines List: edition not reviewed for five years, not approved by the Municipal Health Council and not published in an official journal. There were no defined procedures for disclosing the list.

b) Computerized PPS management system: outsourced service, restricted to inventory management in PHC.

c) Electronic medical record: pharmacists had access to patient data in all PPS facilities.

d) Standard operating procedures: outdated and used only by Central Pharmacy staff. 


\subsection{Organizational culture in PHC}

The organizational culture has 04 indicators (Table 6). The pharmacists working in the municipal health system did not know each other. There was no integration strategy between pharmacists and their work processes. The organizational culture has 04 indicators. Some pharmacists working in the municipal health system did not know each other. There was no integration strategy between pharmacists and their work processes. Some evidences of these we can found in pharmacists citations.

Pharmacist of Central Pharmacy: "When I started working here ..., there was no PPS, we worked, each pharmacist in his workplace. We didn't have any contact between us, some of us didn't even know each other and that made the job very bad and very unrelated".

Pharmacist of the Specialized Care Dispensing Center said: "Specialized service has always been a very isolated sector of PHC".

PHC workers expressed dissatisfaction with the lack of support for PPS actions. The nursing team managed the stock besides deliver medicines to patients. This caused overload. The following quotes illustrate this point.

Pharmacist in Specialized and Judicial Dispensing Center: "Until 2017, the municipality did not have a policy for PPS, we had pharmacists working one in each pharmacy, in the PHC pharmacies, in the out, in the specialized pharmacy, each one worked individually, not as a team or a group".

Secretary of Health in 2017said: "When I arrived and took over the portfolio of the health department, PPS was quite confused, there was no line or better a municipal policy for PPS, and this is what we need today,. We are not only ensuring insuring costs or expenses, but working with what public money in a responsible way. So, we had a very messy house, a lot of expired medicine and put in stock, something that today we prioritize the right purchase, good purchase, right and something that each health center worked on dispensing medication in the way that best suits them".

\section{Discussion}

The results of this article revealed the complexity involved in a PPS system. A Municipal PPS is characterized as an open system and interrelates with the municipal management and the municipal health systems as described in Fig. 1. Within the sociotechnical approach, these larger systems represent the environment of the municipal PPS.

The used index shows sustainability as the balanced development of the social, cultural, environmental, economic, and political dimensions. Despite the political weaknesses, the studied municipality showed good economic development. Its health indicators have a high average level. Social participation was the only indicator that was below average [23]. We can better understand some aspects of the sociotechnical nature of PPS in this context in which it did not please stakeholders.

The aim of the organizational structure is identified as the central element of the model. The other system components interrelate with its scope. For municipal managers, health professionals, and users the lack of medicines was the main frustration. The central aim of the Municipal Health Plan and PPS was the same. It was "to have medicine available from the Municipal List of Medicines in the dispensing centers". This aim exposes a conceptual reduction. Ensuring access to medicines is making them available. A broader perspective comes from WHO: availability is a dimension of access to medicines. So are affordability, acceptability, and rational use of medicines [41, 42]. In Brazil, access is the purpose of PPS and involves its many dimensions [4]. It is more complex than the mere availability of medicines.

Medicine availability is a key part ofthePPS architecture. This dimension can suffer many constraints. We need supply-side strategies to ensure medicine availability and help expand access to medicines in health care systems [43]. But when a PPS system chooses medicine availability as a central goal, its commitment is narrowed down to delivering medicines. Barreto and Guimarães, and Rover and Leite discussed the constraintsof this approach for PPS development in public health systems $[8,6]$.

We identify weaknesses in the PPS management component generated. Lack of central coordination, pharmaceutical services with more than a manager, and a fragmented organization prevented integrated planning with other sectors (Fig. 2). At the health secretariat, there were no human resources available to plan the actions that involved the services. PPS issues were discussed and decisions were made with no integration of the directorates (PHC, specialized services, or warehouse). In 76\% of Brazilian municipalities PPS coordination is nominated in the health department organization chart [10].

PPS has a management logic based on an input distribution model. The environment refers only to technical elements of the system: infrastructure, technical process, and technology. The social components of workforce and culture are not mentioned in the Municipal Health Plan. But, the organizations' reality is based on social components. People are essential sociotechnical elements, as well as the components affecting them [44]. The architecture of municipal PPS should not ignore general and organizational culture.

We did not find working groups organized in the municipal PPS. The working group is considered the elementary construction of the sociotechnical structure. Self-regulation, semi-autonomy, and specific functions but with interrelated tasks are working group features. What connects the groups is to achieve a common goal. This increases the capacity to meet the demands of the internal and external environments [30].

The organizational culture established was the culture of isolation: "each one does their own". People working in the health system did not know each other in a municipality system with only 130,000 inhabitants. There were no shared symbols or collective rituals. The ideology was based on the care logic of contribution. The national pharmaceutical policy advocates PPS with a comprehensive approach to the health-disease process [8, 9, 10, 11]. 
The distribution and dispensing centers' infrastructure is the indicator that showed the best result. The result is better than those observed in other municipalities in the state [45]. But, the infrastructure does not seem to be enough to provide articulated pharmaceutical services. This component is connected to the PPS aim, restricted to distributing medicines.

The processes of the municipal PPS emphasized medicine supply. We highlight the regulation of technical processes for making medicines available. It involved prescription, acquisition, inventory control, and dispensing. Even with technical components in focus, pharmacists did not take part in planning or executing scheduling and purchasing services. In most municipalities in the state, this process involves the pharmacist. This reality impacts on availability, reasonableness of costs, and sustainability of access. In view of the volume of financial resources allocated, this aspect is fundamental [45]. Processes that need intersectionality and participation, such as a Pharmacy and Therapeutics Committee and participatory planning, have not been carried out either.

In the technology component, PPS management at PHC did not meet the needs of prescribers or patients. The problems involved both the diversity of medication available and their recurrent scarcity. Here the key factors are: the formal constitution of the Pharmacy and Therapeutics Committee; and the consumption of $10 \%$ of the budget bu the "non-selected medicines' program". In both situation, there were no defined access criteria. These factors are like those found in the studies by Hoepfner and Gerlack[45, 10].

We can understand the weaknesses of the municipal PPS by looking at some results obtained by the system. The resource used for the PPS (R\$ 38.90 / inhabitant) is higher than the national or state average (R\$20.00) [46]. Even with a high cost, the observed effects show professionals' and users' dissatisfaction as well as a waste of medicines. What works in one configuration may not work elsewhere. We must adapt improvements to the local context and check. The sociotechnical systems approach is capable of answering to local specificities. It also helps to produce incremental results and contributes to building flexible organizational structures $[17,30]$. Understanding the municipal PPS as a sociotechnical system contributed to developing an intervention project. For Carayon et al. (2011), such understanding has the ability to transfer and put in place new knowledge and methods to impact the entire health system [43].

The results presented here suggest that the municipal PPS is a complex system, like the one Appelbaum found [30]. In a sociotechnical intervention, there are many strengths. They should be used within a strategic plan for organizational development instead of as an isolated approach. Policymakers and managers should target their support to systemic solutions, rather than contributing to proliferate fragmented efforts.

Some limitations of this study need to be highlighted. One difficulty is collecting data from different and poorly systematized sources. The lack of good electronic systems and transparency of public data weaken the ability to study this field. The scarcity of references to sociotechnical systems applied to PPS required the adaptation of study instruments, such as the management capacity assessment protocol, besides using references from administration and sociology.

\section{Conclusion}

The study revealed that a municipal PPS implemented had limited scope as a public policy. It had constrained characteristics as a complex and open system. Stakeholders understood PPS as a set of technical processes, without planning or integration. Its absence in the health secretariat organization's chart symbolizes the poor understanding of the system in its policy dimension.

The municipal PPS was a fragmented resource and produced unsatisfactory results. The aim focused on the availability of medicines; this subverts the logic of a system whose purpose is to provide access to medicines. PPS was reduced to the availability of the input, with a low capacity to promote advances in health care. Even if pharmacists had technical-scientific training for developing clinical pharmaceutical services, the situation found in the municipality did not offer the minimum conditions for doing so.

PPS has had a great development in Brazil in the last twenty years. A new level requires a turning point of strategy to understand municipal PPS as a sociotechnical system. It will allow advancing its contribution to the health care process.

\section{Abbreviations}

\section{AHP}

Annual Health Program

MHP

Municipal health plans

REMUME

Municipal List of Medicines

AMMC

Assessment Matrix of the Management Capacity

IBGE

Brazilian Institute of Geography and Statistics

SIDEMS

System of Sustainable Municipal Development Indicators

UDI

Human Development Index

MHS 
Municipal Health Secretariat

PHC

Primary health care

SUS

Brazilian Unified Health System

PPS

Pharmaceutical policy and services

\section{Declarations}

\section{Ethics approval and consent to participate:}

This study is part of a project called "Application of Sociotechnical Theory in the Reorientation of Pharmaceutical Care in Primary Health Care". It was approved by the Univali Research Ethics Committee (CAAE: 28471320.2.0000.0120). All participants signed a written form of consent after having received information about the study.

\section{Consent for Publication:}

Participants have consented the publication.

\section{Availability of data and material:}

All original data can be accessed by authors contact.

\section{Competing interests:}

The authors declare no competing interests.

\section{Funding:}

not applicable.

\section{Authors' contributions:}

NLMB performed the data collection and analyses; LS contribute in analyses and discussion; SNL coordinated the project, the data analyses and final writing. All authors have read and approved the manuscript.

\section{Acknowledgements:}

We would like to acknowledged the health professionals, managers and patients from the municipal health system that participated in this project.

\section{References}

1. Kruk ME, Gage AD, Arsenault C, Jordan K, Leslie HH, Roder-DeWan S, et al. High-quality health systems in the Sustainable Development Goals era: time for a Revolution. The Lancet Global Health Commission. 2018;6. doi:10.1016/S2214-109X(18)30386-3.

2. WHO. Urgent health challenges for the next decade. 2020. https://www.who.int/news-room/photo-story/photo-story-detail/urgent-health-challenges-forthe-next-decade. Accessed 01 may 2020.

3. $10.1111 /$ tmi. 12123

Holloway KA, Ivanovska V, Wagner AK, Vialle-Valentin C, Ross-Degnan D. Have we improved use of medicines in developing and transitional countries and do we know how to? Two decades of evidence. Trop Med Int Health. 2013;18(6):656 - 64. https://doi.org/10.1111/tmi.12123. Accessed 27 Oct 2019.

4. Brasil. Ministério da Saúde. Conselho Nacional de Saúde. Resolução n. 338, de 6 de maio de 2004. Aprova a Política Nacional de Assistência Farmacêutica. https://bvsms.saude.gov.br/bvs/saudelegis/cns/2004/res0338_06_05_2004.html. Accessed 27 Oct 2019.

5. Marin N, Luiza VL, Osorio-de-Castro CGS, Machado-dos-Santos S. Assistência farmacêutica para gerentes municipais. Rio de Janeiro: OPAS/OMS; 2003.

6. Rover M, Leite SN. Gestão em saúde e gestão da assistência farmacêutica. In: Leite SN, Farias MR, Manzini F, Mendes SJ, Rover. MRM. Gestão da assistência farmacêutica: proposta para avaliação no contexto municipal: a experiência em Santa Catarina. Florianópolis: Editora da UFSC; 2015. pp. 39-58.

7. Oliveira MA, Luiza VL, Tavares NUL, Mengue SS, Arrais PSD, Farias MR, et al. Acesso a medicamentos para doenças crônicas no Brasil: uma abordagem multidimensional. Rev. Saude Publica. 2016:50 Suppl 2:6 s. http://www.rsp.fsp.usp.br/wp-content/uploads/articles_xml/0034-8910-rsp-s2-S0151887872016050006161/0034-8910-rsp-s2-S01518-87872016050006161-pt.x99338.pdf. Accessed 27 Oct 2019.

8. Barreto JL, Guimarães MC. Avaliação da gestão da assistência farmacêutica básica em municípios baianos. Brasil Cad Saúde Pública. 2010;26(6):1207-20.

9. Leite SN, Farias MR, Manzini F, Mendes SJ, Rover MRM. Gestão da assistência farmacêutica: proposta para avaliação no contexto municipal: a experiência em Santa Catarina. Florianópolis: Editora da UFSC; 2015. 
10. Gerlack LF, Karnikowski MGO, Areda CA, Galato D, Oliveira AG, Álvares J, et al. Gestão da Assistência Farmacêutica na Atenção Primária no Brasil. Rev. Saude Publica. 2017;51 Suppl. 2:15 s. http://www.scielo.br/pdf/rsp/v51s2/pt_0034-8910-rsp-S1518-51-s2-87872017051007063.pdf. Accessed 27 Oct 2019.

11. Leite SN, Manzini F, Veiga A, Lima MEO, Pereira MA, Araujo SQ, et al. Science, Technology and Pharmaceutical Policy on the agenda: contributions from the society to the 16th National Conference on Health. CienSaude Colet. 2018;23(12):4259-68. https://pubmed.ncbi.nlm.nih.gov/30540009/. Accessed 06 May 2019.

12. Akerman M, Freitas O. Pesquisa Nacional sobre Acesso, Utilização e Promoção do Uso Racional de Medicamentos (PNAUM): avaliação dos serviços de atenção farmacêutica primária. Saúde Pública. 2017;51 Suppl 2:1 s-5 s. https://www.ncbi.nlm.nih.gov/pmc/articles/PMC5676376/. Accessed 27 Oct 2019.

13. Barros RD, Costa EA, Santos DB, Souza GS, Álvares J, Guerra Junior AA, et al. Acesso a medicamentos: relações com a institucionalização da assistência farmacêutica. Rev Saude Publica. 2017;51 Suppl 2:8 s. https://www.scielo.br/pdf/rsp/v51s2/pt_0034-8910-rsp-S1518-51-s2-87872017051007138.pdf. Accessed 01 may 2020.

14. Brasil. Ministério da Saúde. Secretaria de Ciência, Tecnologia e Insumos Estratégicos. Departamento de Assistência Farmacêutica e Insumos Estratégicos. Assistência Farmacêutica no SUS: 20 anos de políticas e propostas para desenvolvimento e qualificação: relatório com análise e recomendações de gestores, especialistas e representantes da sociedade civil organizada [recurso eletrônico]. Brasília: Ministério da Saúde; 2018. http://www.as.saude.ms.gov.br/wp-content/uploads/2019/11/AF-no-SUS-20-Anos-de-Pol\%C3\%ADticas-e-Propostas-para-Desenvolvimento-eQualifica\%C3\%A7\%C3\%A3o.pdf. Accessed 01 may 2020.

15. Botla L, Kondur H. Socio Technical Systems of a Company: The Dimensionality of Socio Technical Systems. Purshartha, mar-aug.2018;XI(1).

16. Emery FE, Trist EL. The causal texture of organization environments. Human Relations. Feb 1965. https://journals.sagepub.com/doi/10.1177/001872676501800103. Accessed 27 Oct 2019.

17. Meeks DW, Takian A, Sittig D, Singh H, Barber N. Exploring the sociotechnical intersection of patient safety and electronic health record implementation. Journal of the American Medical Informatics Association. 2014;21(1):e28-34. Disponívelem: https://www.ncbi.nlm.nih.gov/pubmed/24052536. Accessed 27 Oct 2019.

18. Novak LL, Holden RJ, Anders SH, Hong JY, Karsh BT. Using a sociotechnical framework to understand adaptations in health IT implementation. Int J Med Inform. 2013;82(12):e331-44. https://www.ncbi.nlm.nih.gov/pubmed/23562140. Accessed 27 Oct 2019.

19. Sittig DF, Ash J. On the importance of using a multidimensional sociotechnical model to study health information technology. Annals of Family Medicine. 2011;9(5):390-1. https://www.ncbi.nlm.nih.gov/pubmed/21911756. Accessed 27 Oct 2019.

20. Harvey J, Avery AJ, Ashcroft DM, Boyd MJ, Phipps DL, Barber N. Exploring safety systems for dispensing in community pharmacies: Focusing on how staff relate to organizational components. Research in social \& administrative pharmacy. 2015;11(2):216 - 27. https://www.sciencedirect.com/science/article/pii/S155174111400103X?via\%3Dihub. Accessed 27 Oct 2019.

21. Szeinbach S, Seoane-Vazquez E, Parekh A, Herderick M. Dispensing errors in community pharmacy: perceived influence of sociotechnical factors. Int J Qual Health Care. 2007 Aug;19(4):203-9.

22. Brusque IBGE. Censo. 2010. https://cidades.ibge.gov.br/brasil/sc/brusque. Accessed 01 may 2020.

23. SIDEMS.Índice de Desenvolvimento Sustentável dos Municípios Catarinenses. 2017. https://indicadores.fecam.org.br/indice/estadual/ano/2017. Accessed 01 may 2020.

24. Brusque. Annual management report. 2017. https://brusque.atende.net/\#!/tipo/acesso-informacao/valor/especifico/item/5. Accessed 01 may 2020.

25. Barreto JL, Guimarães MCL. Avaliação da gestão descentralizada da assistência farmacêutica básica em municípios baianos, Brasil. Cadernos de Saúde Pública. 2016;26(6):1207-20.

26. Phipps DL, Noyce PR, Parker D, Ashcroft DM. Medication safety in community pharmacy: a qualitative study of the sociotechnical context. BMC Health Services Research. 2009;9:158. https://www.ncbi.nlm.nih.gov/pmc/articles/PMC2745376/pdf/1472-6963-9-158.pdf. Accessed 01 may 2020.

27. Sittig DF, Singh H. A new sociotechnical model for studying health information technology in complex adaptive healthcare systems. Quality \& Safety in Health Care. 2010;19 Suppl 3:68-74. https://www.ncbi.nlm.nih.gov/pubmed/20959322. Accessed 27 Oct 2019.

28. Harvey J, Avery AJ, Waring J, Barbieri N. The socio-technical organisation of community pharmacies as a factor in the Electronic Prescription Service Release Two implementation: a qualitative study. BMC Health Services Research. 2012;12:471.

https://www.ncbi.nlm.nih.gov/pmc/articles/PMC3551639/pdf/1472-6963-12-471.pdf. Accessed 01 may 2020.

29. Leavitt HJ. Applied organizational change in industry: structural, technological, andhumanistic approaches. In: March JG. Handbook of organizations. Chicago: RandMcNally\& Co.; 1965. pp. 1144-70.

30. Appelbaum S. Socio-technical systems theory: An intervention strategy for organizational development. Management Decision. 1997;35(6):452 - 63. https://www.researchgate.net/publication/235266179_Sociotechnical_systems_theory_An_intervention_strategy_for_organizational_development/stats.Accessed 27 Oct 2019.

31. Toronto, Ontario: Ministry of Labor/Ontario Quality of Working Life Center (Issues in the quality of working life: a serie of occasional papers, $\mathrm{n} 2$ ).

Trist EL. The evolution of socio-technical system. Toronto, Ontario: Ministry of Labor/Ontario Quality of Working Life Center; 1981. (Issues in the quality of working life: a serie of occasional papers, $\mathrm{n} 2$ ).

32. Davis MC, Challenger R, Jayewardene DNW, Clegg CW. Advancing socio-technical systems thinking: A call for bravery. Apperson. 2014;45(2)Part A:171 80. https://www.sciencedirect.com/science/article/abs/pii/S000368701300032X. Accessed 27 Oct 2019.

Page 13/16 
33. Clegg CW. Sociotechnical principles for system design. ApplErgon. 2000;31(5):463 - 77. https://www.ncbi.nlm.nih.gov/pubmed/11059460. Accessed 27 Oct 2019.

34. Challenger R, Clegg CW. Crowd disasters: a socio-technical systems perspective. Contemporary Social Science. 2011;6(3):343-60. doi: 10.1080/21582041.2011.619862. Accessed 01 may 2020.

35. Guimarães MCL, Santos SMC, Melo C, Sanches Filho A. Avaliação da capacidade de gestão de organizações sociais: uma proposta metodológica em desenvolvimento. Cad Saúde Pública [online]. 2004;20(6):1642-50. https://www.scielo.br/scielo.php?pid=S0102-311X.

$2004000600023 \&$ script=sci_abstract\&tlng=pt. Accessed 06 abr 2020..

36. Lima MG, Álvares J, Guerra Junior AA, Costa EA, Guibu IA, Soeiro OM, et al. Indicadores relacionados ao uso racional de medicamentos e seus fatores associados. Rev Saude Publica. 2017;51 Suppl 2:23 s. https://www.scielo.br/pdf/rsp/v51s2/pt_0034-8910-rsp-S1518-51-s2-87872017051007137.pdf. Accessed 01 may 2020.

37. Brusque. Annual Health Program in the municipality. 2015:29. http://webcache.googleusercontent.com/search? q=cache:mVdvMbM2E98J:controlesocial.saude.sc.gov.br/index.php\%3Foption\%3Dcom_jdownloads\%26ltemid\%3D94\%26view\%3Dfinish\%26cid\%3D2989 BR\&ct=clnk\&gl=br\&client=firefox-b-d. Accessed 06 may 2020.

38. Brusque. Câmara Municipal de Brusque. Complementary Law No. 224/2014: institutes the Municipal Health Code, which defines pharmacy as a health service and medicines as products subject to sanitary. http://www.legislador.com.br/LegisladorWEB.ASP?

WCI=LeiTexto\&ID=11\&inEspecieLei=2\&nrLei=224\&aaLei=2014\&dsVerbete=medicamento. Accessed 06 may 2020.

39. Brusque. Secretaria Municipal de Saúde. Normative No. 005/2015. https://portal.brusque.sc.gov.br/secretaria/secretaria-de-saude/. Accessed 06 may 2020.

40. Brusque DN. 7826, July 8, 2016. https://leismunicipais.com.br/a/sc/b/brusque/decreto/2016/782/7826/decreto-n-7826-2016-disciplina-procedimentosa-serem-adotados-pelos-medicos-e-odontologos-servidores-publicos-municipais-e-prestadores-de-servico-para-o-sistema-unico-de-saude-em-ambitomunicipal-na-prescricao-de-medicamentos-e-na-solicitacao-de-exames-e-procedimentos-de-saude-e-estabelece-outras-providencias. Accessed 06 may 2020.

41. WHO. The World Medicines Situation. 2nd editor. 2004. https://apps.who.int/iris/handle/10665/68735. Accessed 01 may 2020.

42. WHO

WHO. Access and rational use of strategic 1 and high-cost medicines and other health technologies.

2016.https://www.paho.org/hq/dmdocuments/2016/CD55-10-e.pdf. Accessed 01 may 2020.

43. $10.1377 /$ hlthaff.28.4.962

Frost LJ, Reich MR. Creating Access To Health Technologies In Poor Countries. Health Affairs. 2009;28(4):962 - 73.

https://www.healthaffairs.org/doi/pdf/10.1377/hlthaff.28.4.962. Accessed 01 may 2020.

44. Carayon P, Bass E, Bellandi T, Gurses A, Hallbeck S, Mollo V. Sociotechnical systems analysis in health care: a research agenda. IIE Transactions on Healthcare Systems Engineering. 2011;1(1):145-160. https://www.ncbi.nlm.nih.gov/pmc/articles/PMC3351758/pdf/nihms356690.pdf. Accessed 27 Oct 2019.

45. Hoepfner L. Diagnóstico da Assistência Farmacêutica Pública em Santa Catarina: Uma Avaliação. [Especialização em Gestão em Saúde]. Florianópolis: Universidade Federal de Santa Catarina; 2019.

46. CONASEMS. Entrevista Mauro Junqueira CONASEMS. Entrevista Mauro Junqueira. Revista CONASEMS. 2018;72:05-10.https://www.conasems.org.br/wpcontent/uploads/2019/02/Conasems_Revista_72_Web_F01.pdf. Accessed 01 may 2020.

\section{Figures}




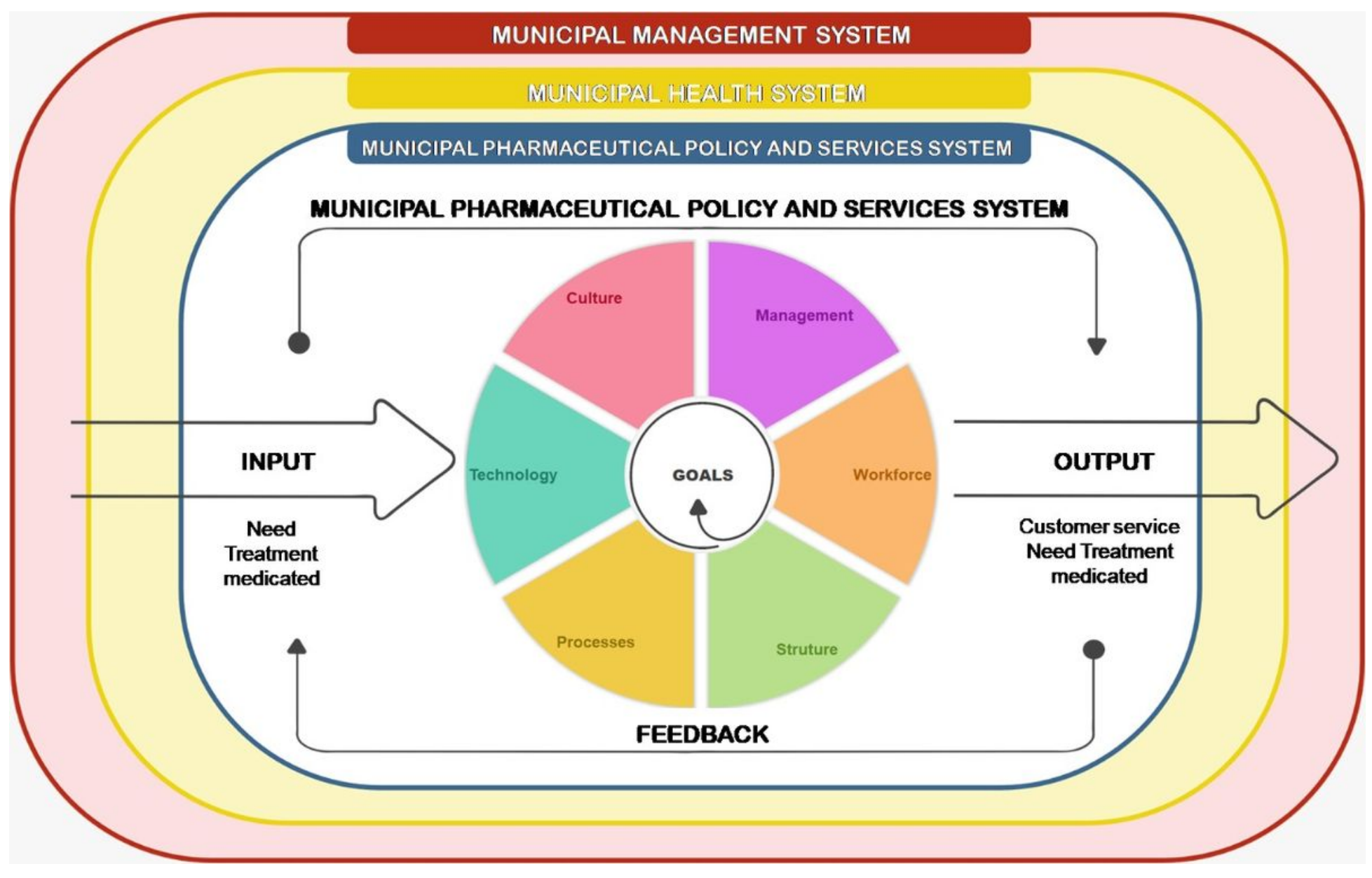

Figure 1

Sociotechnical model for the municipal PPS, showing the system components for the analytical procedures Source: the authors 


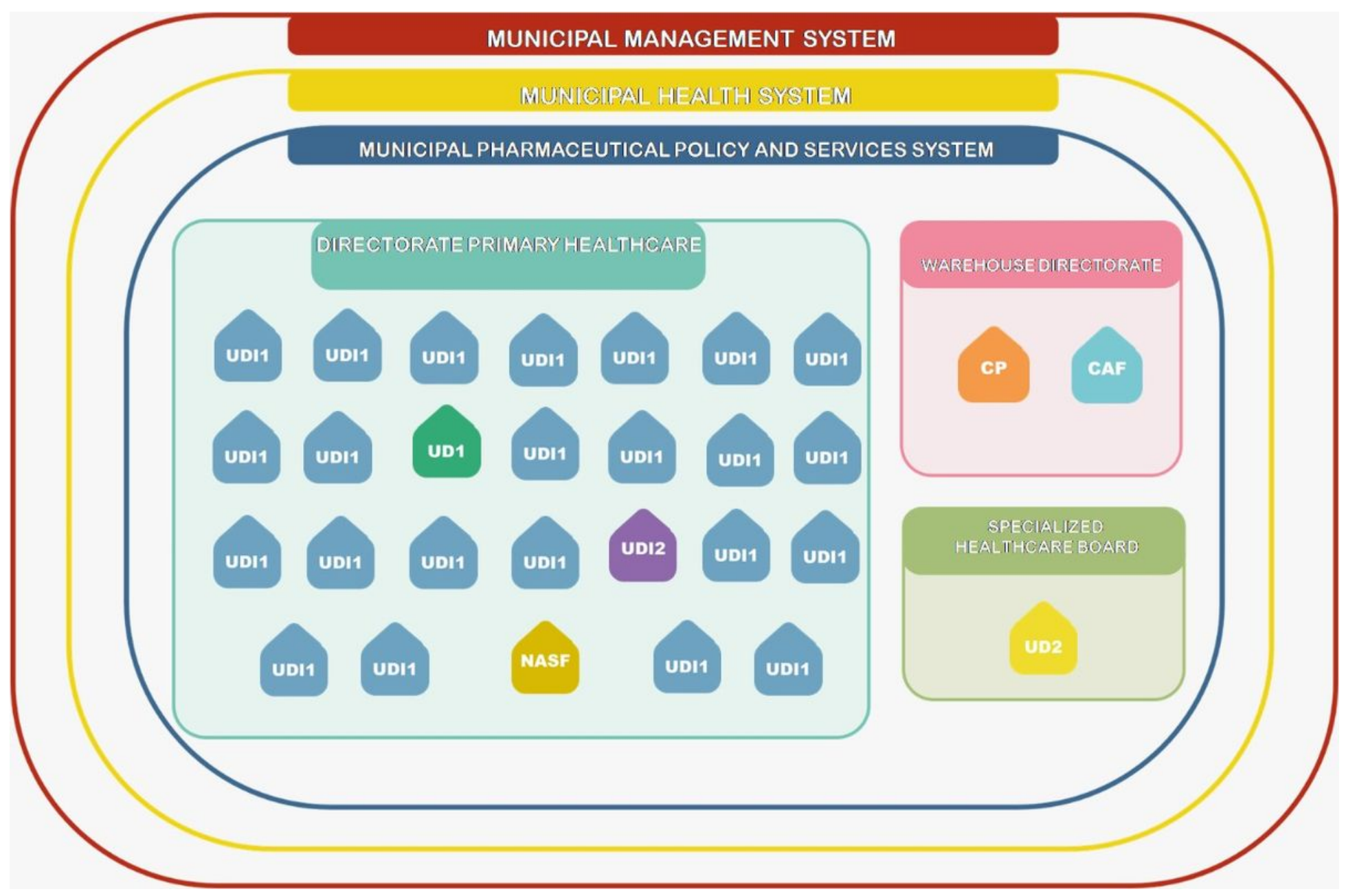

Figure 2

Organizational structure of Municipal PPS in 2017, in the municipality under study. Legend: -UDI1: Dispensing unit in PHC unit; -UDI2: Dispensing unit in specialized care service (medications for STI / AIDS, leprosy, tuberculosis and other strategic control diseases for Ministry of Health); -UD1:Central Pharmacy PHC medications dispensing center; -UD2:Specialized and Judicial Dispensing Unit (mainly high-priced drugs, for rare or chronic diseases or for judicial access); -CP: Purchasing department; -CAF:Pharmaceutical Distribution and Supply Center; -NASF: Family Health Support Center (Ministry of Health program to support PHC). Source: the authors. 